Folletti, I., Zock, J.P., Moscato, G., Siracusa, A. Asthma and rhinitis in cleaning workers: a systematic review of epidemiological studies. Journal of Asthma: 2014, 51(1), 18-28

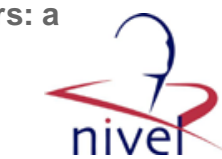

\begin{tabular}{|l|l|}
$\begin{array}{l}\text { Postprint } \\
\text { Version }\end{array}$ & 1.0 \\
\hline Journal website & http://informahealthcare.com/doi/abs/10.3109/02770903.2013.833217 \\
\hline Pubmed link & $\underline{\text { http://www.ncbi.nlm.nih.gov/pubmed/23931651 }}$ \\
\hline DOI & $10.3109 / 02770903.2013 .833217$ \\
\hline
\end{tabular}

This is a NIVEL certified Post Print, more info at http://www.nivel.eu

\title{
Asthma and rhinitis in cleaning workers: a systematic review of epidemiological studies
}

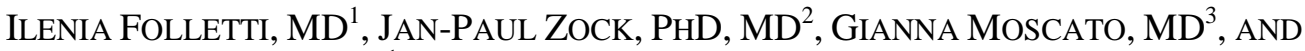 \\ ANDREA SIRACUSA, MD ${ }^{1}$ \\ ${ }^{1}$ Occupational Allergology Unit, Department of Clinical and Experimental Medicine, \\ University of Perugia, Perugia, Italy, \\ ${ }^{2}$ Centre for Research in Environmental Epidemiology (CREAL), Hospital del Mar Research \\ Institute (IMIM) and CIBER Epidemiología y Salud Pública (CIBERESP), Barcelona, Spain, \\ and \\ ${ }^{3}$ Allergy and Immunology Unit, Fondazione Salvatore Maugeri, Institute of Care and \\ Research, Scientific Institute of Pavia, Pavia, Italy
}

\begin{abstract}
Objective: This article presents a systematic review of epidemiological studies linking cleaning work and risk of asthma and rhinitis. Methods: Published reports were identified from PubMed covering the years from 1976 through June 30, 2012. In total, we identified 24 papers for inclusion in the review. The quality of studies was evaluated using the Strengthening of the Reporting of Observational Studies in Epidemiology (STROBE) statement checklist of 22 items for cross-sectional, cohort and case-control studies. Results: Increased risk of asthma or rhinitis has been shown in $79 \%$ of included epidemiological studies. In four studies the increased risk of asthma in cleaning workers was confirmed by objective tests, such as bronchial hyper-reactivity or airflow obstruction. Level of exposure to cleaning products, cleaning sprays, bleach, ammonia, mixing products and specific job tasks has been identified as specific causes of asthma and rhinitis. Conclusions: Possible preventive measures encompass the substitution of cleaning sprays, bleach and ammonia, avoidance of mixing products, the use of respiratory protective devices, worker education and medical surveillance.
\end{abstract}

\section{INTRODUCTION}

Cleaning anything involves making something else dirty, but anything can get dirty without something else getting clean (Laurence J Peter, US educator and writer, 1919-1988). 
Folletti, I., Zock, J.P., Moscato, G., Siracusa, A. Asthma and rhinitis in cleaning workers: a systematic review of epidemiological studies. Journal of Asthma: 2014, 51(1), 18-28

Cleaners constitute a large professional group in developed countries. According to EUROSTAT, in 2006 in 20 European countries there were 3.6 million people employed in industrial cleaning [1]. Industrial cleaning accounts for 3\% of total employment in the private sector; most of the employees are females and work parttime while about $30 \%$ of cleaning workers are migrant workers [1,2]. In a survey of 4500 Spanish women, 39\% were current and former domestic cleaners [3]. In surveillance studies carried out in Spain, United States and Brazil cleaning products were among the most reported causes of occupational asthma or work-related asthma (WRA) [4-6] while in United Kingdom and France cases of occupational asthma/WRA due to cleaning products were not frequently reported $[7,8]$. In recent years cleaning has been associated with WRA and work-related rhinitis $[9,10]$.

The epidemiological literature on respiratory health outcomes and risks of cleaners has been reviewed. Two reviews were update on the risk of asthma in cleaners in epidemiological and surveillance studies and case reports for the period 2003-2005 and 2006-2009, respectively [11,12]; 6 and 7 epidemiological studies reporting the assessment of the risk of asthma in cleaners for the period 2003-2005 and 20062009, respectively, were reviewed. Charles et al. reviewed the epidemiological studies reporting all occupational hazards, 1981-2005, 11 of which have assessed the risk of asthma in cleaners [13]. Quirce and Barranco recently reviewed the association between asthma and cleaning but the search strategy was not reported [14]; 7 epidemiological studies have reported the risk of asthma in cleaners. The four reviews have reported neither the evaluation of quality of epidemiological studies nor the risk of rhinitis.

This article presents a systematic review of epidemiological studies linking exposure to cleaning products and the risk of asthma and rhinitis and discusses suggestions for prevention.

\section{METHODS}

\section{Data sources, search strategy and study selection}

Published reports were identified from PubMed covering the years from 1976 through June 30, 2012. We used the following key words search strategy: (cleaning worker* OR cleaning product* OR cleaner* OR bleach OR hypochlorite OR ammonia OR cleaning spray* OR disinfectant*) AND (asthma OR rhinitis OR respiratory). Using this schema we identified 678 potentially eligible citations. In a first selection we discarded 525 papers because they were not in the field of asthma and rhinitis in cleaners and 113 because they were not in English. In a second selection we discarded 20 studies on cleaning workers because they were not epidemiological studies on asthma and rhinitis: eight case reports, five surveillance studies, two exposure studies, five reviews. One study was discarded because it was on skin disease. Nineteen epidemiological studies published in English that reported the odds of asthma/rhinitis associated with exposure to cleaning products were included. We also reviewed all papers for reference citations within 1976-2012 time frame that had not been otherwise identified in the initial search and we identified an additional 5 studies for inclusion. In total we identified 24 papers for inclusion in the systematic review. 
Folletti, I., Zock, J.P., Moscato, G., Siracusa, A. Asthma and rhinitis in cleaning workers: a systematic review of epidemiological studies. Journal of Asthma: 2014, 51(1), 18-28

\section{Quality assessment}

The quality of observational studies was evaluated using the Strengthening of the Reporting of Observational Studies in Epidemiology (STROBE) statement checklist of 22 items for cross-sectional, cohort and case-control studies [15]. Data for quality assessment were extracted using a standard record sheet which included the checklist of 22 items independently by two reviewers (IF and AS). Discrepancies were resolved by consensus. The studies were classified into the following three categories: A, more than $80 \%$ of STROBE criteria fulfilled; B, $50-80 \%$ of STROBE criteria fulfilled; and C, less than 50\% of STROBE criteria fulfilled [16]. 20 studies were classified into category A, 4 in category B, and none in category C (Tables 1 and 2).

\section{[TABLE 1][TABLE 2]}

\section{Definitions}

We defined cleaning workers (cleaners) as people whose paid or unpaid work involves cleaning of public or private buildings. In this definition, we include employed non-domestic and domestic indoor cleaners as well as non-professional home cleaners (homemakers). We do not include other jobs involving the use of cleaning products at work such as health care professionals and food industry workers.

The definition of asthma was based on symptoms gathered from the following questionnaires (Tables 1 and 2):

- European Community Respiratory Health Survey (ECRHS) questionnaire in 16 studies;

- Third National Health and Nutrition Examination Survey (NHANES III) questionnaire [17];

- French Pollution Atmosphérique et Affections Respiratoires Chroniques (PAARC) Survey questionnaire [18];

- previously validated questionnaires [1];

- Helsinki Office Environmental Study modified questionnaire [20];

- non-validated questionnaires [21,22].

Reported asthma was confirmed by a physician (physician-diagnosed asthma) in 2 studies [19,23]. The definition of asthma was based on symptoms and objective tests, such as assessment of bronchial reactivity through a methacholine challenge test [2426], airflow limitation through a forced spirometric test [18] or reversibility of airways obstruction in five studies [20].

The diagnosis of rhinitis was always based on symptoms [10,27-29]. 
Folletti, I., Zock, J.P., Moscato, G., Siracusa, A. Asthma and rhinitis in cleaning workers: a systematic review of epidemiological studies. Journal of Asthma: 2014, 51(1), 18-28

\section{RESULTS}

We selected 24 epidemiological studies on asthma or rhinitis in subjects exposed to cleaning products evaluated for methodological quality [15]: 7 cross-sectional and 3 longitudinal population-based studies, 7 case-control studies, 5 cross-sectional and 2 longitudinal studies in working groups. Potential source of information and/or selection biases were discussed in all studies. Direction and magnitude of bias was examined in three studies [24,30,31]. Study size was not explained in one crosssectional study [29]. It was unclear if 3 studies were free of commercial funding $[18,21,29]$. In 7 studies, the participation rate was not specified (Tables 1-3).

\section{[TABLE 3]}

\section{Cross-sectional population-based studies (Table 1)}

Seven cross-sectional population-based studies, ranging from 1975 to 2006, showed an association between exposure to cleaning products and:

- $\quad$ asthma symptoms, with a risk estimate between 1.5 and 2.5 [3,24,25,32,33];

- asthma symptoms and bronchial hyper-reactivity, odds ratio (OR) 2.5 (95\% confidence interval (CI) 1.03-6.2) and OR 2.0 (95\% CI 1.3-2.9), respectively [24,25];

- asthma symptoms with airflow limitation, OR 2.5 (95\% CI 1.3-4.7) [18]. In one study, there was a non-statistically significant association between exposure to cleaning products and WRA (OR 2.4, 95\% CI 0.5-10.6) [17].

\section{Longitudinal population-based studies (Table 1)}

Longitudinal population-based studies showed an association between exposure to cleaning products and incidence of:

- adult new-onset asthma (OR 1.8, 95\% CI 1.01-3.2) [34];

- adult new-onset non-infectious rhinitis (OR 2.1, 95\% CI 1.1-4.0) [27];

- adult new-onset perennial rhinitis (OR 1.4, 95\% CI 1.0-2.1) [28].

\section{Case-control studies (Table 1)}

In three studies there was an association between cleaning work and asthma symptoms or severe asthma symptoms, with a risk estimate between 1.9 and 7.4 $[21,35,36]$. Medina-Ramón et al. showed an association between intermediate (OR 23, 95\% CI 1.9-274) or high exposure to bleach (OR 14, 95\% CI 1.3-153) and asthma symptoms [37]. Weekly use of more than two types of sprays was associated with asthma symptoms (OR 2.5, 95\% CI 1.5-4.0), current asthma (OR 1.7, 95\% CI 1.1-2.6) and poorly-controlled asthma (OR 2.0, 95\% CI 1.2-3.3) [31]. In two studies, there was no association between cleaning work and asthma with reversible airway obstruction or severe exacerbation of asthma [20,38]. 
Folletti, I., Zock, J.P., Moscato, G., Siracusa, A. Asthma and rhinitis in cleaning workers: a systematic review of epidemiological studies. Journal of Asthma: 2014, 51(1), 18-28

\section{Cross-sectional studies in working groups (Table 2)}

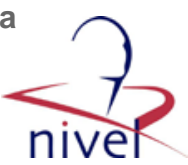

Between 1998 and 2011, five studies were published in Europe, North America and Brazil, four of which showed an association between exposure to cleaning products and:

- $\quad$ asthma symptoms, with a risk estimate between 1.7 and 3.3 [26,30];

- asthma symptoms and bronchial hyper-reactivity, with a risk estimate between 2.8 (95\% CI 1.3-6.2) and 5.0 (95\% CI 1.9-13.2) [26];

- rhinitis symptoms (OR 2.1, 95\% CI 1.2-3.7) [10].

In one study, there was no difference in the prevalence of asthma/rhinitis between 40 cleaners and 40 controls [29].

The exposure to cleaning products was evaluated in various occupations, such as professional [10,19,26,29,30] or domestic cleaners [26]. In Brazilian non-domestic cleaners rhinitis symptoms were 3 times more frequent than asthma symptoms [10].

\section{Longitudinal studies in working groups (Table 2)}

One longitudinal study in working groups demonstrated in Spanish home cleaners an association between exposure to cleaning sprays and the incidence of asthma symptoms, with a risk estimate of 1.5 (95\% CI 1.1-2.0) [23]. In one report asthma was higher in former cleaners than in current cleaners [22].

\section{Confounding variables and risk factors (Table 3)}

In the majority of studies the risk of asthma or rhinitis was simultaneously adjusted for the potential confounding variables sex, age and smoking. In three studies female gender was a risk factor for WRA, rhinitis or perennial rhinitis $[10,19,28]$. On the contrary, Hellgren et al. showed an association between male gender and rhinitis [27].

In current domestic cleaners, the risk of asthma decreased with increasing age while in a cohort of female cleaners age was not a risk factor for asthma [3,22].

The potential relationship between smoking and asthma in subjects exposed to cleaning agents was investigated in five studies. In one cross-sectional study in working groups current smoking was a risk factor (OR 3.2, 95\% CI 1.4-7.2) [10] while in one cross-sectional population-based, 2 longitudinal studies in working groups and one case-control study smoking was not a risk factor [22,23,31,32].

Two studies compared the risk of asthma in domestic and non-domestic cleaners: the risk of current asthma was higher in domestic cleaners (OR 1.5, 95\% CI 1.1-1.9) than in non-domestic cleaners (OR 1.1, 95\% CI 0.7-1.6) [3]. The risk of asthma symptoms and asthma symptoms and BHR were higher in private home cleaners (prevalence ratio (PR) 3.3, 95\% CI 1.9-5.8, and PR 5.0, 95\% CI 1.9-13,2, respectively) than in other cleaners (PR 1.0, 95\% CI 0.5-2.0, and PR 1.7, 95\% CI $0.5-5.5$, respectively) [26]. 
Folletti, I., Zock, J.P., Moscato, G., Siracusa, A. Asthma and rhinitis in cleaning workers: a systematic review of epidemiological studies. Journal of Asthma: 2014, 51(1), 18-28

The duration of occupational exposure was associated with the risk of WRA or workrelated rhinitis in non-domestic cleaners while in another study was not associated with asthma $[10,19]$.

Six studies examined the level of exposure as a risk factor. Obadia et al. (2009) showed no association with asthma while Vizcaya et al. showed an association between the exposure to the number of different workplace or products used and asthma [19,30]. In three reports, the level of exposure to cleaning sprays or bleach was associated with asthma [23,31,37]. On the contrary, Nielsen and Back showed no significant association with the level of exposure to cleaning sprays [22].

The risk of asthma or rhinitis was associated with exposure to various cleaning products [26,34,36], tasks [19], exposure to cleaning sprays, ammonia, bleach or hydrochloridric acid [10,23,26,30] or mixing products [26,37]. However, in a study on female cleaners cleaning sprays were not a significant risk factor for asthma [22]. Interestingly enough, using liquid cleaning products was negatively associated with asthma [37].

In two studies, atopy was a risk factor for asthma and rhinitis [10,24] while in several other studies atopy was not a risk factor [23,26,32,37]. In other papers, the risk of asthma or rhinitis was adjusted for atopy [21,24,27].

Socio-economic status has seldom been examined as a risk factor for asthma in subjects exposed to cleaning products. In a few studies the risk of asthma or rhinitis was adjusted for socio-economic status $[23,28,33]$ while Zock et al. demonstrated that socio-economic status was not a confounding factor for the risk of asthma [32].

\section{DISCUSSION}

The results of our review indicate that exposure to cleaning products in various jobs/tasks and settings increase the risk for asthma and rhinitis. This is also supported by the results of several surveillance studies from various countries [4-6] although in other studies from other countries cases of occupational asthma/WRA due to cleaning products were not frequently reported $[7,8]$. In four studies the risk of asthma was confirmed by objective tests, such as bronchial hyper-reactivity or airflow obstruction supporting the results of studies in which the definition of asthma was based on symptoms only (Tables 1 and 2) [18,24-26]. Domestic cleaners tended to have a higher risk of asthma than non-domestic cleaners as it was also confirmed in a focus group study [3,26,39].

In Brazilian cleaners, rhinitis symptoms were 3 times more prevalent than asthma symptoms [10]. Similarly, in workers exposed to sensitizing agents occupational rhinitis tended to be 3 times more frequent than occupational asthma [40].

In subjects exposed to cleaning products, level of exposure may be the main risk factor (Table 3), in agreement with observations on occupational asthma and rhinitis $[40,41]$. In a few cases specific products, such as ammonia, bleach and cleaning sprays were associated with asthma or new-onset asthma $[23,26,37,42]$ and a dose- 
Folletti, I., Zock, J.P., Moscato, G., Siracusa, A. Asthma and rhinitis in cleaning workers: a systematic review of epidemiological studies. Journal of Asthma: 2014, 51(1), 18-28

response relationship between the use of bleach or cleaning sprays and asthma or new-onset asthma was also demonstrated [23,37]. Massin et al. measured concentration levels of chloramines, often derived from mixing bleach with dishwashing liquid, and aldehydes and assessed respiratory symptoms among 175 cleaning and disinfecting workers in the food industry [43]; a dose-response relationship between eye, nasal and throat symptoms and exposure levels was found. Exposure studies showed that airborne exposure levels of chlorine and ammonia were detectable at concentrations $\geq 0.1 \mathrm{ppm}$ during domestic cleaning work and the use of concentrated ammonia solutions (e.g. 3\%) in poorly ventilated areas may produce significant ammonia exposure [37,44]. Moreover, the large use of common sprays at home may have significant implications for public health; e.g. Zock et al. estimated that one in seven adult asthma cases may be related to the use of household cleaning sprays [23].

In a few studies gender was analysed as risk factor with contradictory results (Table 3). In a cross-sectional study in working groups non-domestic female cleaners were at increased risk of WRA (OR 3.9, 95\% CI 2.1-7.4) [19], while gender was not a risk factor for asthma in a cross-sectional population based study [32]. The risk of rhinitis was associated with male cleaners or female cleaners $[27,28]$. Contradictory results were also reported in population-based epidemiological studies, although females tended to have a higher risk factor for asthma and rhinitis more often than males [4548].

In one cross-sectional population based study, the risk of asthma decreased with increasing age [3], in agreement with cohort studies in apprentices bakers/pastry makers or exposed to laboratory animals or latex, in which WRA and work-related rhinitis tended to occur within the firs 2-3 years of exposure [49].

In one study, only atopy was a risk factor for asthma and rhinitis and smoking was a risk factors for asthma (109) while in several others atopy and smoking were not risk factors $[23,26,32,37]$. The risk in subjects exposed to cleaning products seems not dependent on atopic status, supporting the view that asthma and rhinitis are mainly due to irritants and low-molecular weight agents [23,26,30,42]. Moreover, there is little to support that the risk of asthma and rhinitis is increased in smokers exposed to cleaning products, in agreement with a review on smoking and occupational asthma [50].

One limitation of studies in exposed to cleaning products is that occupational asthma and work-exacerbated asthma has seldom been differentiated. However, in health care professional exposed to cleaning products the prevalence of occupational asthma and work-exacerbated asthma was $0.8 \%$ and $1.1 \%$, respectively [51].

\section{Suggestion for prevention}

Occupational asthma and rhinitis are considered potentially preventable diseases $[52,53]$. It is surprising that prevention of work-related respiratory diseases in cleaners has been neglected by the biomedical research in spite of a large body of knowledge on the dimension of the problem (Tables 1 and 2) and identification of 
Folletti, I., Zock, J.P., Moscato, G., Siracusa, A. Asthma and rhinitis in cleaning workers: a systematic review of epidemiological studies. Journal of Asthma: 2014, 51(1), 18-28

specific products and job tasks responsible for asthma and rhinitis symptoms (Table $3)$.

In fact, the review of 24 epidemiological studies suggests possible preventive intervention with the aim of improving respiratory health in cleaners, such as:

- substitution of cleaning sprays with liquid multi-use cleaning products [23,26,37];

- substitution of bleach and ammonia with less irritating product [10,26,37,42,51]. Particularly, the substitution of hypochlorite bleach is highly recommended and feasible, as was recently shown in six hospitals of Eastern Massachusetts where bleach was not used [54];

- avoidance of mixing cleaning products, especially bleach with other products [26,37];

- ingredients of cleaning agents could be pretested for their ability to cause sensitization.

Most cases of WRA in cleaners are due to exposure to one or more irritants and unidentified ingredients which need further evaluation while a minority are associated with sensitizers [10,30,34,37,42,55-60]. Moreover, preventive interventions are more difficult in domestic cleaners and occupational domestic cleaners, in spite of the fact that they are at higher risk of asthma and respiratory symptoms than professional cleaners, perhaps because of lower or no worker education, lack of awareness regarding risks, protective clothing and respiratory devices and no surveillance [23,26,36,37,39].

There is evidence that in the last 2-3 decades, the prevalence and incidence of occupational asthma and rhinitis due to laboratory animals, isocyanates, and latex decreased over time, suggesting benefit from preventive measures [61-63]. Unfortunately, time trends for asthma and rhinitis or controlled intervention studies in cleaners are not available.

A public health approach contributing to reduce hazardous cleaning product use was described in the study of Pechter et al. performed on immigrant cleaning workers [64]. Improved conditions were obtained by eliminating the most hazardous chemicals, reducing the number of products used, banning mixing products and improving safety training. Unfortunately, in the paper there was no control of the alleged improved conditions on work-related respiratory symptoms of immigrant cleaning workers.

An interesting example of prevention is included in a New York State law, effective September 1, 2006, which requires that in all elementary and secondary schools environmentally sensitive cleaning products must be used in order to minimize adverse impact on children's health but also, as a "by-product", on cleaners health, as reported by Mazurek et al. [4]. 
Folletti, I., Zock, J.P., Moscato, G., Siracusa, A. Asthma and rhinitis in cleaning workers: a systematic review of epidemiological studies. Journal of Asthma: 2014, 51(1), 18-28

\section{CONCLUSIONS}

A number of epidemiological studies have identified that domestic and professional cleaning work, especially when associated with the use of household cleaning sprays, bleach and ammonia or exposure to mixing products, may have relevant implications for public health [65]. It has been estimated that a number of adult asthma cases, e.g. up to one in seven cases, could be attributed to the use of sprays. Several risk factors were also identified, allowing the development of effective prevention strategies. Unfortunately, the conclusion of research on cleaners and consequent policy implications have not been heeded by commercial cleaning stakeholder organizations, such as manufactures, vendors and commercial cleaning companies. However, collaboration between scientific communities and European safety and health agencies may improve the respiratory health of workers and citizens exposed to cleaning products.

\section{ACKNOWLEDGEMENT}

We thank Katherine Brandt Tonato for reviewing the article.

\section{DECLARATION OF INTEREST}

The authors report no conflicts of interest. The authors alone are responsible for the content and writing of this article.

\section{REFERENCES}

Brun E, editor. The occupational safety and health of cleaning workers. Luxemburg: EUOSHA -- European Agency for Safety and Health at Work; 2009

Björnsson K. Industrial cleaning: outsourcing versus in-house production. EUROSTAT statistics in focus - Industry, trade and services, Theme 4, 2/1999

Medina-Ramon M, Zock JP, Kogevinas M, Sunyer J, Antó JM. Asthma symptoms in women employed in domestic cleaning: a community based study. Thorax 2003;58:950-954

Mazurek JM, Filios M, Willis R, Rosenman KD, Reilly MJ, McGrevy, Schill DP, et al. Workrelated asthma in the educational services industry: California, Massachusetts, Michigan, and New Jersey, 1993-2000. Am J Ind Med 2008;51:47-59

Mendonça EM, Algranti E, Freitas JBP, Rosa EA, Freire JAS, Santos UP, Pinto J, Bussacos MA. Occupational asthma in the city of São Paulo, 1995-2000, with special reference to gender analysis. Am J Ind Med 2003;43:611-617

Orriols R, Costa R, Albanell C, Alberti C, Castejon J, Monso E, Panades R, et al; Members of the Malaltia Ocupacional Respiratòria (MOR) Group. Reported occupational respiratory diseases in Catalonia. Occup Environ Med 2006;63:255-260

Kopferschmitt-Kubler MC, Ameille J, Popin E, Calastreng-Crinquand A, Vervloet D, BayeuxDunglas MC, Pauli G. Occupational asthma in France: a 1-yr report of the Observatoire National de Asthmes Professionnels project. Eur Respir J 2002;19:84-89

McDonald JC, Keynes HL, Meredith SK. Reported incidence of occupational asthma in the United Kingdom, 1989-97. Occup Environ Med 2000;57:823-829

Arif AA, Delclos GL, Serra C. Occupational exposures and asthma among nursing professionals. Occup Environ Med 2009;66:274-278

Maçãira de Fátima E, Algranti E, Coeli Mendonça EM, Bussacos MA. Rhinitis and asthma symptoms in non-domestic cleaners from São Paulo metropolitan area, Brazil. Occup Environ Med 2007;64:446-453 
Folletti, I., Zock, J.P., Moscato, G., Siracusa, A. Asthma and rhinitis in cleaning workers: a systematic review of epidemiological studies. Journal of Asthma: 2014, 51(1), 18-28

Jaakkola JJK, Jaakkola MS. Professional cleaning and asthma. Curr Opin Allergy Clin Immunol. 2006;6:85-90

Zock J-P, Vizcaya D, Le Moual N. Update on asthma and cleaners. Curr Opin Allergy Clin Immunol 2010;10:114-120

Charles LE, Loomis D, Demissie Z. Occupational hazards experienced by cleaning workers and janitors: a review of the epidemiologic literature. Work. 2009;34:105-116

Quirce S, Barranco P. Cleaning agents and asthma. J Investig Allergol Clin Immunol 2010;20:542-550

Von Elm E, Altman DG, Egger M, Pocock SJ, Gøtzsche PC, Vandenbroucke JP, for the STROBE Initiative. The Strengthening the Reporting of Observational Studies in Epidemiology (STROBE) statement: guidelines for reporting observational studies. J Clin Epidemiol 2008;61:344-349

Mendy A, Gasana J, Vieira ER, Forno E, Patel J, Kadam P, Ramirez G. Endotoxin exposure and childhood wheeze and asthma: a meta-analysis of observational studies. J Asthma 2011;48:685-693

Arif AA, Delclos GL, Whitehead LW, Tortolero SR, Lee ES. Occupational exposures associated with work-related asthma and work-related wheezing among U.S. workers. Am $\mathrm{J}$ Ind Med 2003;44:368-376

Le Moual N, Kennedy SM, Kauffmann F. Occupational exposures and asthma in 14,000 adults from the general population. Am J Epidemiol 2004;160:1108-1116

Obadia M, Liss GM, Lou W, Purdham J, Tarlo SM. Relationship between asthma and work exposure among non-domestic cleaners in Ontario. Am J Ind Med 2009;52:716-723

Jaakkola JJK, Piipari R, Jaakkola MS. Occupation and asthma: a population-based incident case-control study. Am J Epidemiol 2003;158:981-987

Ng TP, Hong CY, Goh LG, Wong ML, Koh KTC, Ling SL. Risk of asthma associated with occupations in a community-based case-control study. Am J Ind Med 1994;25:709-718

Nielsen J, Bach E. Work-related eye symptoms and respiratory symptoms in female cleaners. Occup Med 1999;49:291-297

Zock JP, Plana E, Jarvis D, Antó JM, Kromhout H, Kennedy SM, Künzli N, Villani S, et al. The use of household cleaning spray and adult asthma. An international longitudinal study. Am J Respir Crit Care Med 2007;176:735-741

Kogevinas M, Antó JM, Soriano JB, Tobias A, Burney P, and the Spanish Group of the European Asthma Study. The risk of asthma attributable to occupational exposures. A population-based study in Spain. Am J Respir Crit Care Med 1996;154:137-143

Kogevinas M, Antó JM, Sunyer J, Tobias A, Kromhout H, Burney P, and the European Community Respiratory health Survey Study Group. A population based study on occupational asthma in Europe and other industrialised countries. Lancet 1999;353:17501754

Zock JP, Kogevinas M, Sunyer J, Almar E, Muniozguren N, Payo F Sánchez JL, Antó JM; on behalf of the Spanish working group of the ECRHS. Asthma risk, cleaning activities and use of specific cleaning products in Spanish indoor cleaners. Scand J Work Environ Health. 2001;27:76-81

Hellgren J, Lillienberg L, Jarlstedt J, Karlsson G, Torén K. Population-based study of noninfectious rhinitis in relation to occupational exposure, age, sex, and smoking. Am J Ind Med 2002;42:23-28

Radon K, Gerhardinger U, Schulze A, Zock J-P, Norback D, Toren K, Jarvis D, et al; Occupational Group of the ECRHS study. Occupation and adult onset of rhinitis in the general population. Occup Environ Med 2008;65:38-43

Corradi M, Gergelova P, Di Pilato E, Folesani G, Goldoni M, Andreoli R, Selis L, Mutti A. Effect of exposure to detergents and other chemicals on biomarkers of pulmonary response in exhaled breath from hospital cleaners: a pilot study. Int Arch Occup Environ Health 2011;165:741-748

Vizcaya D, Mirabelli MC, Antó JM, Orriols R, Burgos F, Arjona L, Zock JP. A workforcebased study of occupational exposures and asthma symptoms cleaning workers. Occup Environ Med 2011;68:914-919

Le Moual N, Varraso R, Siroux V, Dumas O, Nadif R, Pin I, Zock JP, Kauffmann F; on behalf of the Epidemiological Study on the Genetics and Environment of Asthma. Domestic use of cleaning sprays and asthma activity in women. Eur Respir J 2012;40:1381-1389 
Folletti, I., Zock, J.P., Moscato, G., Siracusa, A. Asthma and rhinitis in cleaning workers: a systematic review of epidemiological studies. Journal of Asthma: 2014, 51(1), 18-28

Zock JP, Kogevinas M, Sunyer J, Jarvis D, Torén K, Antó JM, for the European Community Respiratory Health Survey. Asthma characteristics in cleaning workers, workers in other risk jobs and office workers. Eur Respir J 2002;20:679-685

Eng A, 'T Mannetje A, Douwes J, Cheng S, McLean D, Ellison-Loschmann L, Pearce N. The New Zealand workforce survey II: occupational risk factors for asthma. Ann Occup Hyg 2010;54:154-164

Kogevinas M, Zock JP, Jarvis D, Kromhout $\mathrm{H}$, Lillienberg L, Plana E, Radon K, et al. Exposure to substances in the workplace and new-onset asthma: an international prospective population based study (ECRHS-II). Lancet 2007;370:336-341

Kennedy SM, Le Moual N, Choudat D, Kauffmann F. Development of an asthma specific job exposure matrix and its application in the epidemiological study of genetics and environment in asthma (EGEA). Occup Environ Med 2000;57:635-641

Le Moual N, Siroux V, Pin I, Kauffmann F, Kennedy SM, on behalf of the Epidemiological Study on the Genetics and Environment of Asthma (EGEA). Asthma severity and exposures to occupational asthmogens. Am J Respir Crit Care Med. 2005;172:440-445

Medina-Ramon M, Zock JP, Kogevinas M, Sunyer J, Torralba Y, Borrell A, Burgos F, Antó $\mathrm{JM}$. Asthma, chronic bronchitis, and exposure to irritant agents in occupational domestic cleaning: a nested case-control study. Occup Environ Med 2005;62:598-606

Henneberger PK, Mirabelli MC, Kogevinas M, Antó JM, Plana E, Dahlman-Höglund A, Jarvis $\mathrm{DL}$, et al. The occupational contribution to severe exacerbation of asthma. Eur Respir J 2010;36:743-750

Arif AA, Hughes PC, Delclos GL. Occupational exposures among domestic and industrial professional cleaners. Occup Med 2008;58:458-463

Siracusa A, Desrosiers M, Marabini A. Epidemiology of occupational rhinitis: prevalence, aetiology and determinants. Clin Exp Allergy 2000;30:1519-1534

Maestrelli P, Boschetto P, Fabbri LM, Mapp CE. Mechanisms of occupational asthma. J Allergy Clin Immunol 2009;123:531-542

Mirabelli MC, Zock JP, Plana E, Antó JM, Benke G, Blanc PD, Dahlman-Höglund A, et al. Occupational risk factors for asthma among nurses and related healthcare professional in an international study. Occup Environ Med 2007;64:474-479

Massin N, Hecht G, Ambroise D, Héry M, Toamain JP, Hubert G, Dorotte M, Bianchi B. Respiratory symptoms and bronchial responsiveness among cleaning and disinfecting workers in the food industry. Occup Environ Med 2007;64:75-81

Fedoruk MJ, Bronstein R, Kerger BD. Ammonia exposure and hazard assessment for selected household cleaning product uses. J Expo Anal Environ Epidemiol 2005;15:534544

Chen Y, Mai XM. Smoking and asthma in men and women with normal weight, overweight, and obesity. J Asthma 2011;48:490-494

Torén K, Ekerljung L, Kim JL, Hillström J, Wennergren G, Rönmark E, Lötvall J, Lundbäck B. Adult-onset asthma in west Sweden - incidence, sex differences and impact of occupational exposures. Respir Med. 2011;105:1622-1628

Matheson MC, Dharmage SC, Abramson MJ, Walters EH, Sunyer J, de Marco R, Leynaert $B$, et al. Early-life risk factors and incidence of rhinitis: results from the European Community Respiratory Health Study - an international population-based cohort study. J Allergy Clin Immunol 2011;128:816-823

Jacquemin B, Kauffmann F, Pin I, Le Moual N, Bousquet J, Gormand F, Just J, et al., on behalf of the Epidemiological study on the Genetics and Environment of Asthma (EGEA). Air pollution and asthma control in the Epidemiological study on the Genetics and Environment of Asthma. J Epidemiol Community Health 2011;66:796-802

Moscato G, Pala G, Boillat MA, Folletti I, Gerth van Wijk R, Olgiati-Des Gouttes D, Perfetti L, et al. EAACI position paper: prevention of work-related respiratory allergies among preapprentices or apprentices and young workers. Allergy 2011;66:1164-1173

Siracusa A, Marabini A, Folletti I, Moscato G. Smoking and occupational asthma. Clin Exp Allergy 2006;36:577-584

Arif AA, Delclos GL. Association between cleaning-related chemicals and work-related asthma and asthma symptoms among healthcare professionals. Occup Environ Med 2012;69:35-40 
Folletti, I., Zock, J.P., Moscato, G., Siracusa, A. Asthma and rhinitis in cleaning workers: a systematic review of epidemiological studies. Journal of Asthma: 2014, 51(1), 18-28

Moscato G, Vandenplas O, Van Wijk RG, Malo JL, Quirce S, Walusiak J, Castano R, et al., EAACI Task Force on Occupational Rhinitis. Occupational rhinitis. Allergy. 2008;63:969980

Tarlo SM, Liss GM. Prevention of occupational asthma. Curr Allergy Asthma Rep 2010;10:278-286

Bello A, Quinn MM, Perry MJ, Milton DK. Characterization of occupational exposure to cleaning products used for common cleaning tasks-a pilot study of hospital cleaners. Environ Health 2009;8:11

Dijkman JH, Vooren PH, Kramps JA. Occupational asthma due to inhalation of chloraminesT. I. Clinical observation and inhalation provocation studies. Int Arch Allergy Appl Immunol 1981;64:422-427

Kujala VM, Reijula KE, Ruotsalainen E-M, Heikkinen K. Occupational asthma to chloramineT solution. Respir Med 1995;89:693-695

Hole AM, Draper A, Jolliffe G, Cullinan P, Jones M, Newman Taylor AJ. Occupational asthma caused by bacillary amylase used in the detergent industry. Occup Environ Med 2000;57:840-842

Rosenman KD, Reilly MJ, Schill DP, Valiante D, Flattery J, Harrison R, Reinisch F, et al. Cleaning products and work-related asthma. J Occup Environ Med 2003;45:556-563

Brant A, Hole A, Cannon J, Helm J, Swales C, Welch J, et al. Occupational asthma caused by cellulase and lipase in the detergent industry. Occup Environ Med 2004;61:793-795

Medina-Ramon M, Zock JP, Kogevinas M, Sunyer J, Basagaña X, Schwartz J, Burge PS, et al. Short-term respiratory effects of cleaning exposures in female domestic cleaners. Eur Respir J 2006;27:1196-1203

Folletti I, Forcina A, Marabini A, Bussetti A, Siracusa A. Have the prevalence and incidence of occupational asthma and rhinitis because of laboratory animals declined in the last 25 years? Allergy 2008;63:834-841

Tarlo SM, Liss GM. Diisocyanate-induced asthma: diagnosis, prognosis, and effects of medical surveillance measures. Appl Occup Environ Hyg 2002;17:902-908

Vandenplas O, Larbanois A, Vanassche F, François S, Jamart J, Vandeweerdt M, Thimpont J. Latex-induced occupational asthma: time trend in incidence and relationship with hospital glove policies. Allergy 2009;64:415-420

Pechter E, Azaroff LS, López I, Goldstein-Gelbs M. Reducing hazardous cleaning product use: a collaborative effort. Public Health Rep 2009;124(Suppl 1):45--52

Bernstein JA, Brandt D, Rezvani M, Abbott C, Levin L. Evaluation of cleaning activities on respiratory symptoms in asthmatic female homemakers. Ann Allergy Asthma Immunol. 2009;102:41--46

\section{TABLES}


Folletti, I., Zock, J.P., Moscato, G., Siracusa, A. Asthma and rhinitis in cleaning workers: a

systematic review of epidemiological studies. Journal of Asthma: 2014, 51(1), 18-28

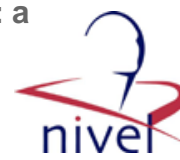

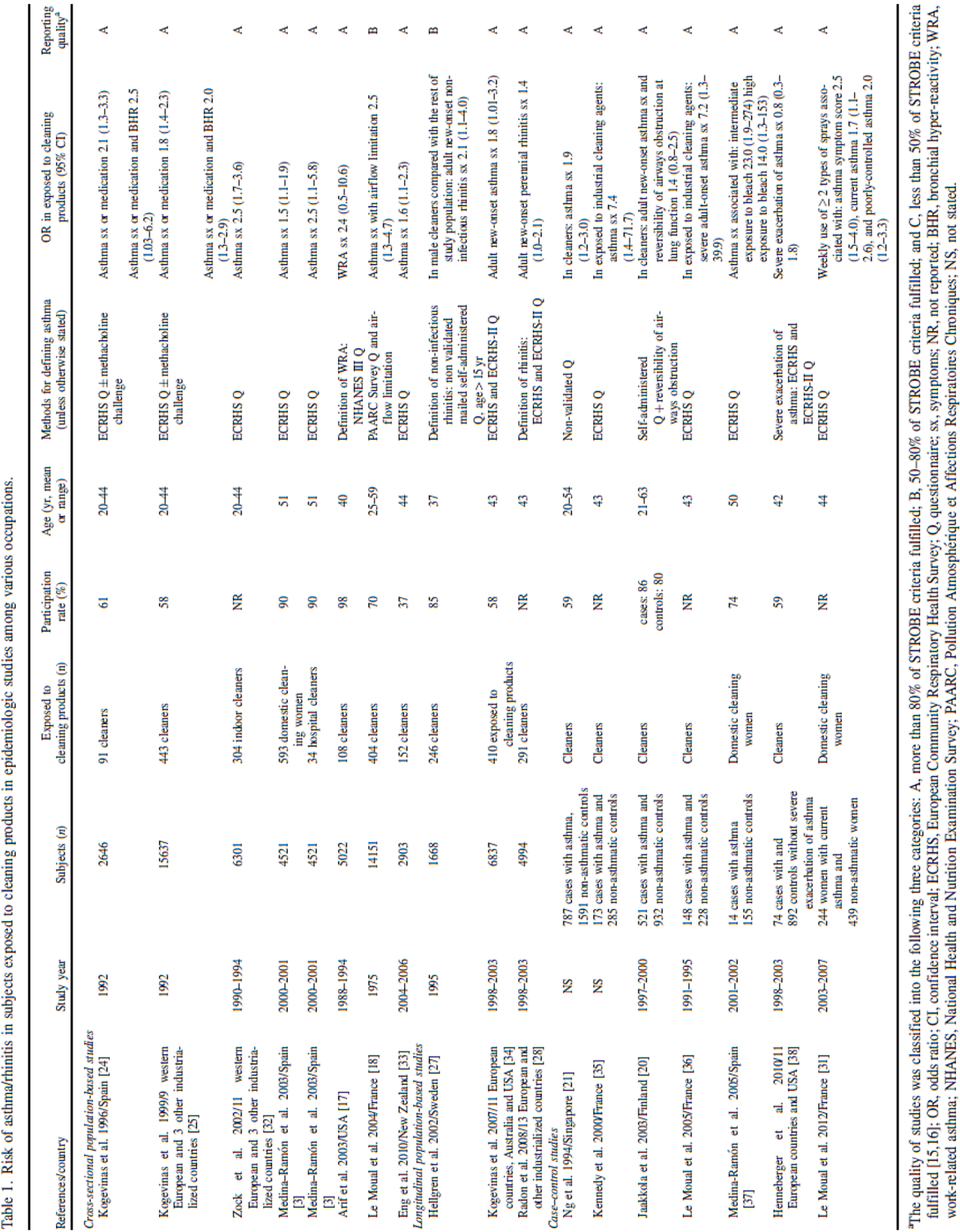


Folletti, I., Zock, J.P., Moscato, G., Siracusa, A. Asthma and rhinitis in cleaning workers: a systematic review of epidemiological studies. Journal of Asthma: 2014, 51(1), 18-28
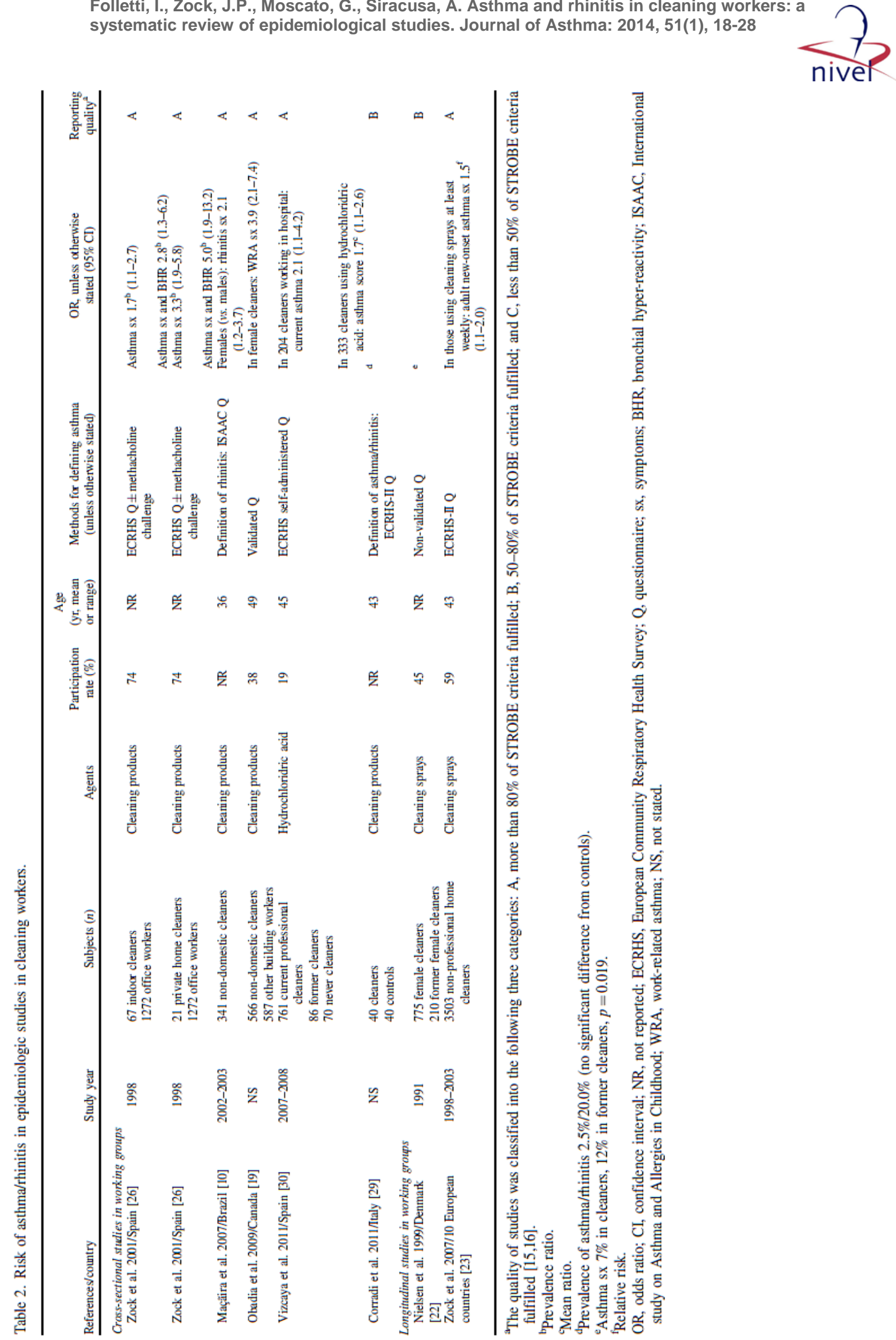
Folletti, I., Zock, J.P., Moscato, G., Siracusa, A. Asthma and rhinitis in cleaning workers: a systematic review of epidemiological studies. Journal of Asthma: 2014, 51(1), 18-28
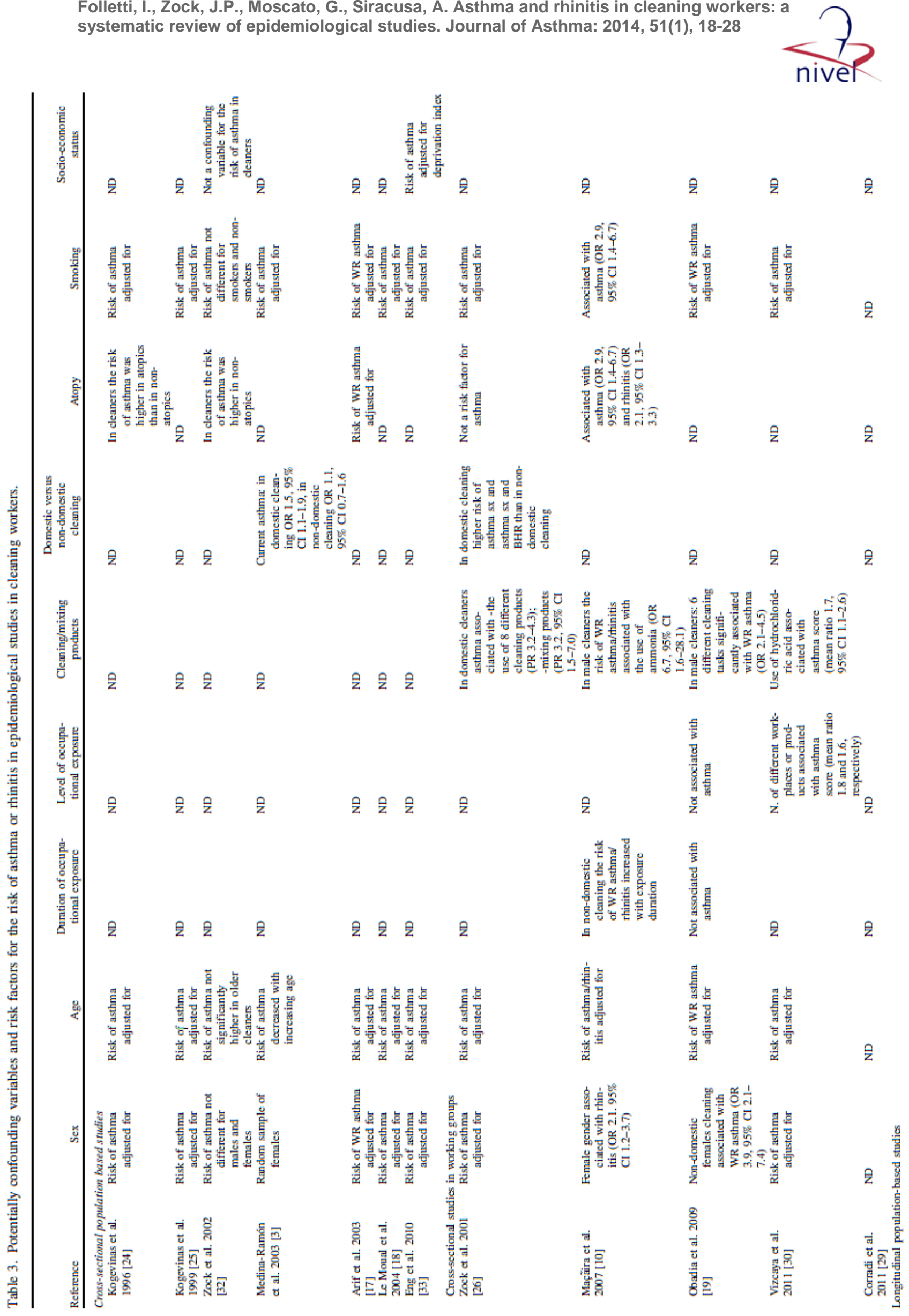
Folletti, I., Zock, J.P., Moscato, G., Siracusa, A. Asthma and rhinitis in cleaning workers: a systematic review of epidemiological studies. Journal of Asthma: 2014, 51(1), 18-28
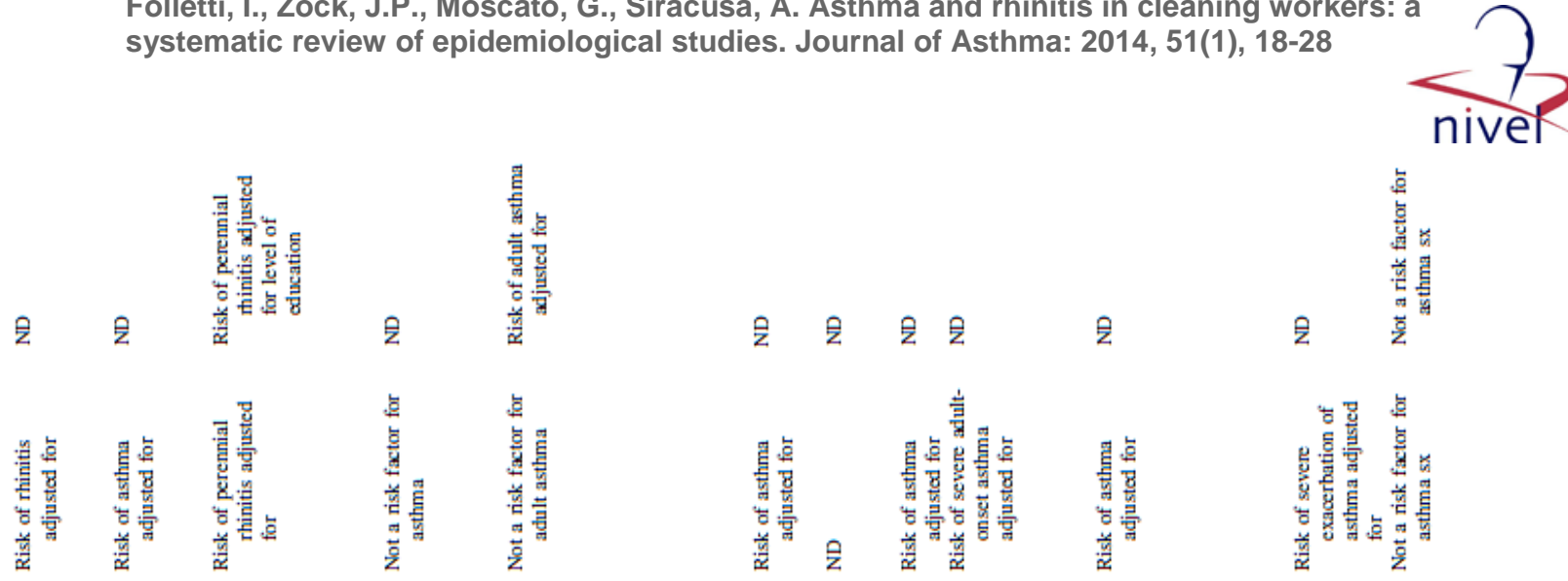

il
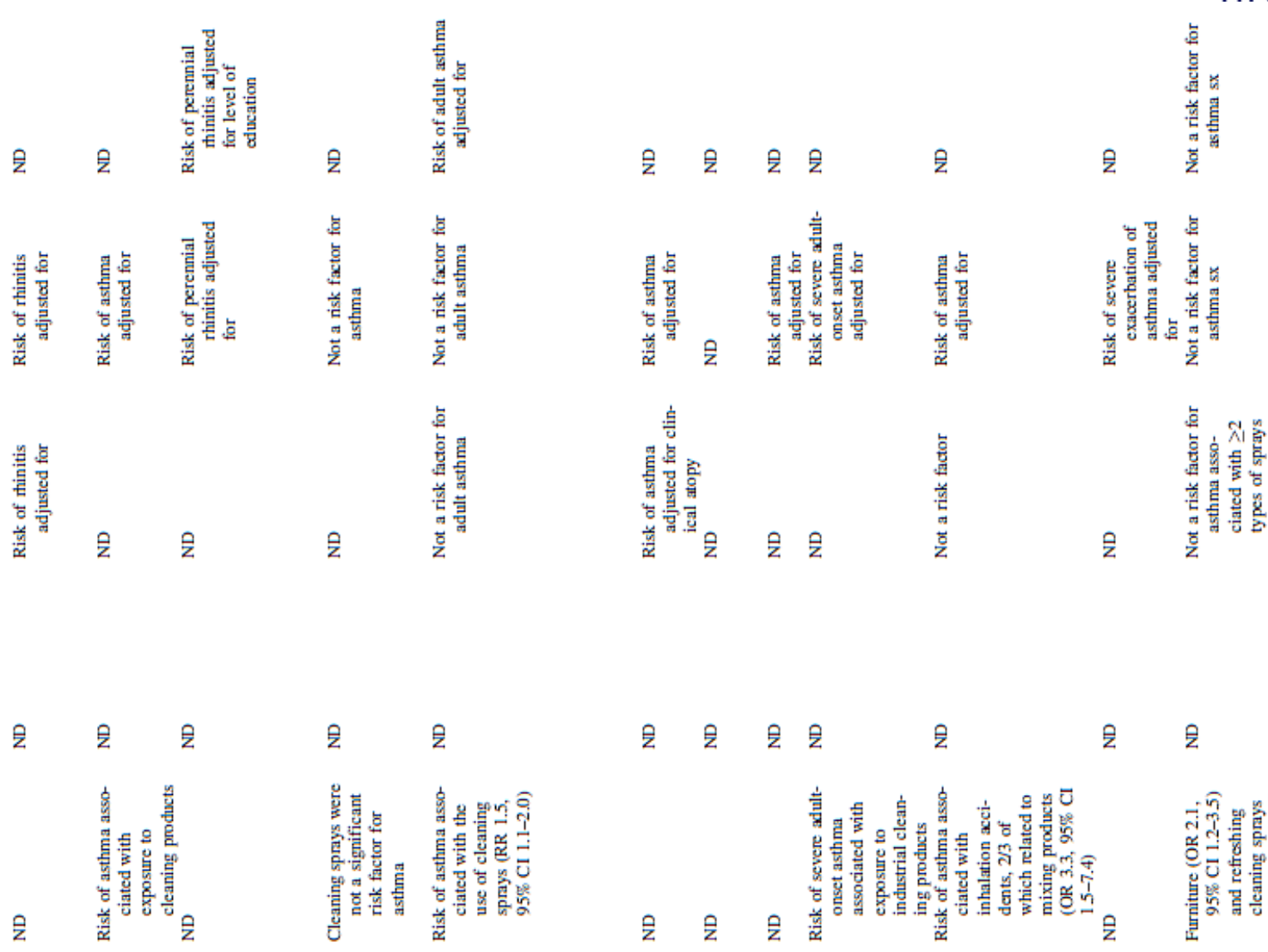

₹ $\mathrm{z}$

合

妾妾
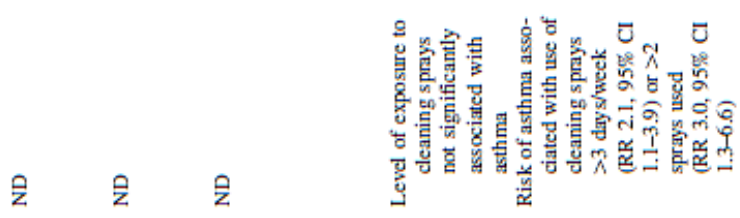

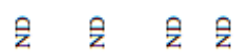
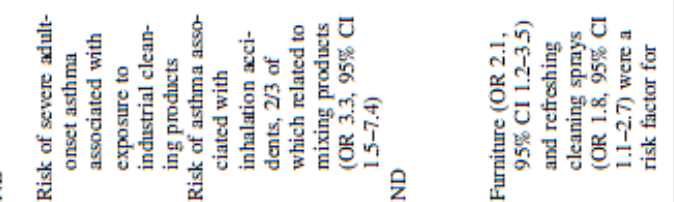

$\frac{\bar{z}}{\mathrm{z}} \quad \mathrm{z}$

rand
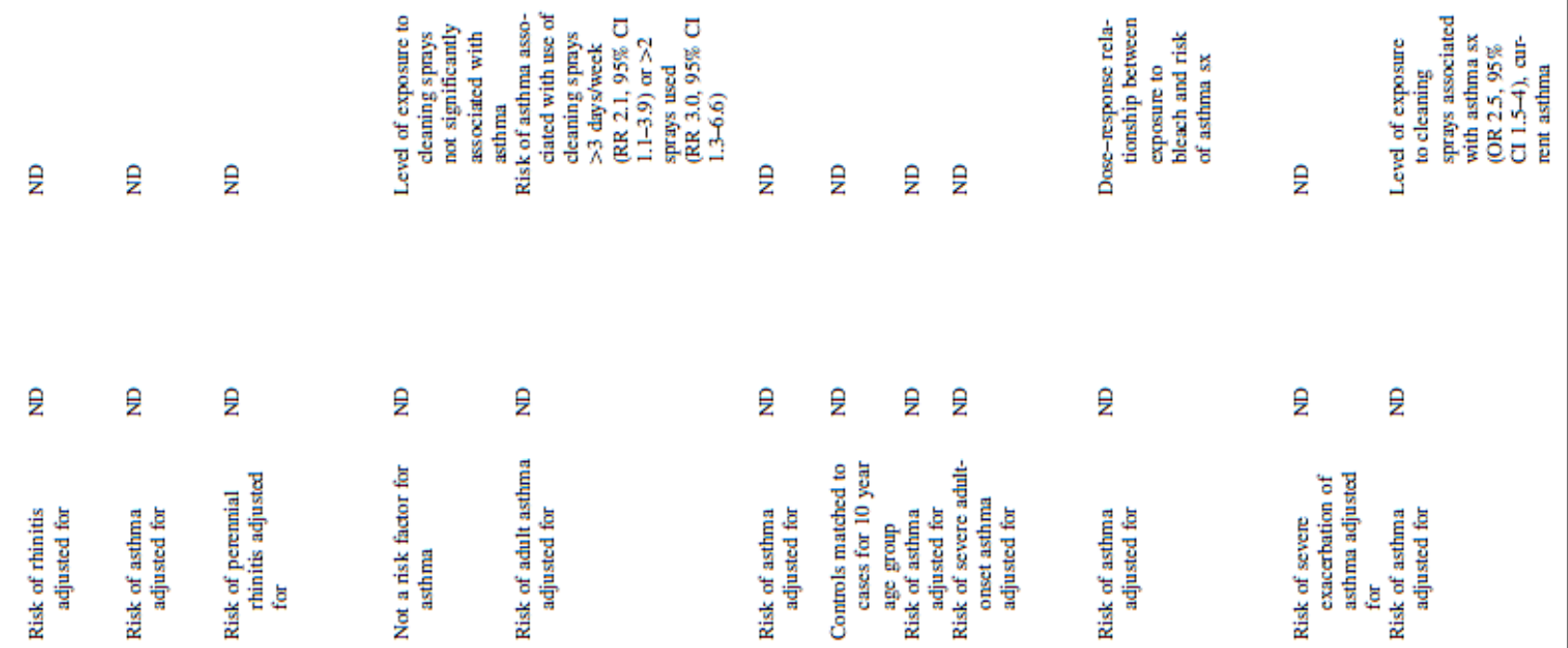

令会会

爷

紊立
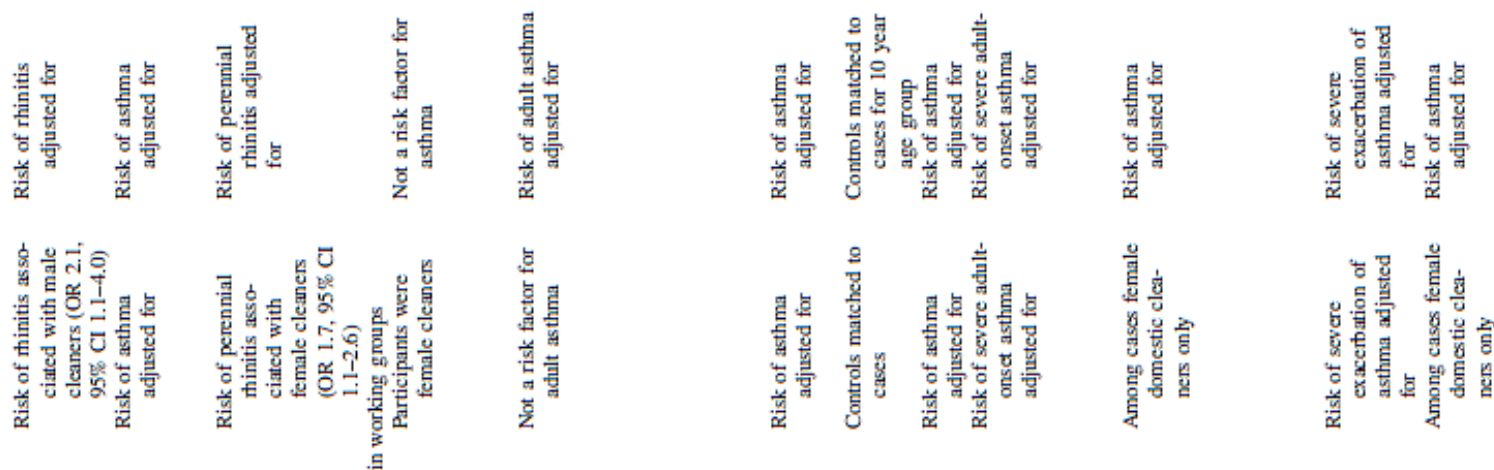

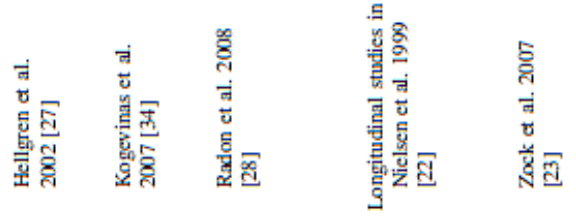
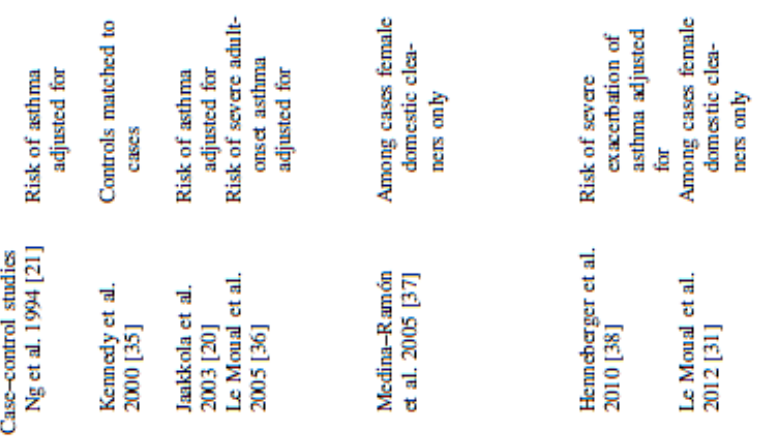

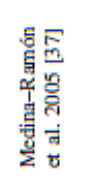

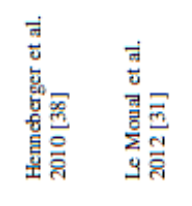


Folletti, I., Zock, J.P., Moscato, G., Siracusa, A. Asthma and rhinitis in cleaning workers: a systematic review of epidemiological studies. Journal of Asthma: 2014, 51(1), 18-28
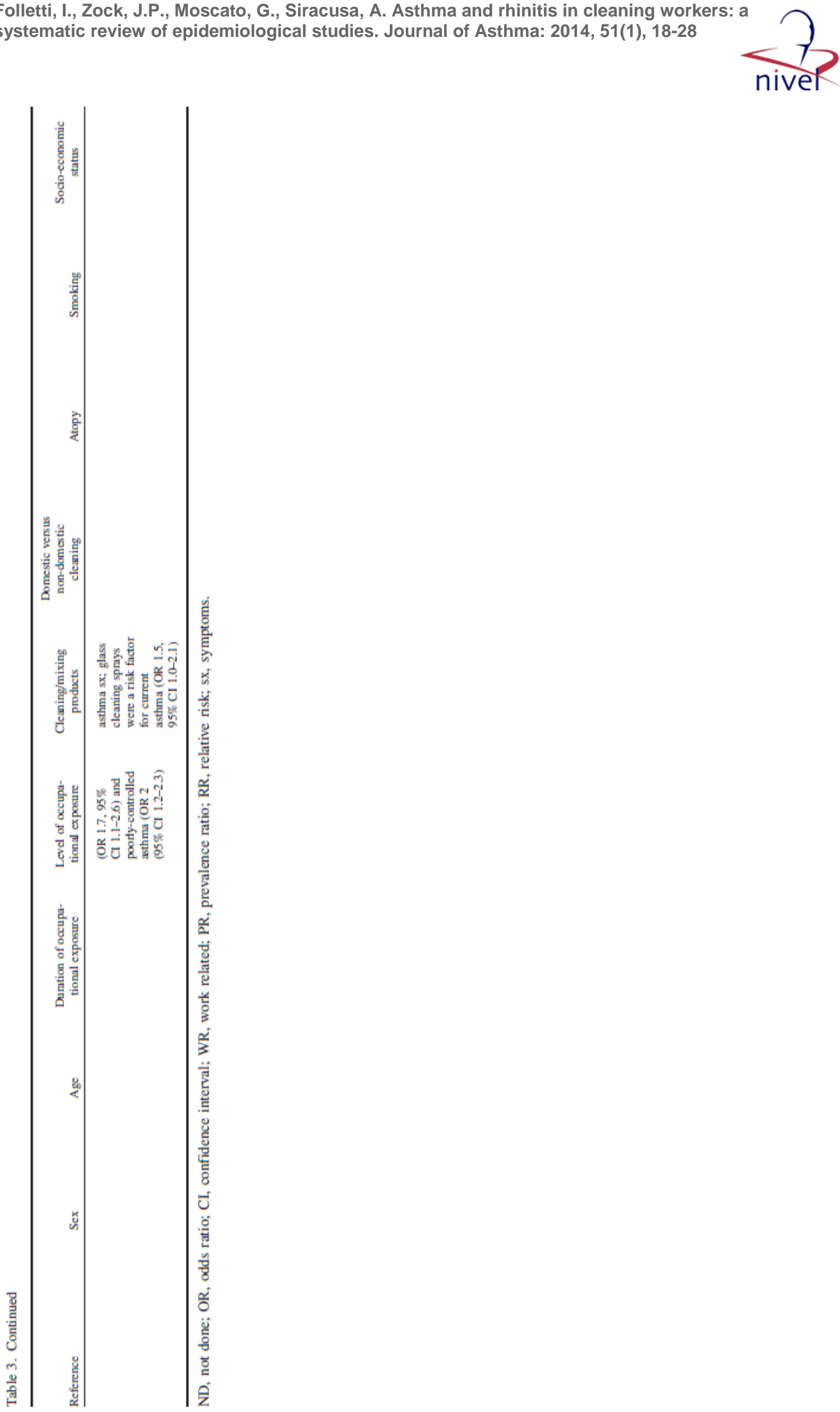